\title{
The Appropriation of Blockchain for Small and Medium-sized Enterprises
}

\author{
Ethem Ilbiz \\ ethemilbiz@gmail.com | Visiting Research Fellow at the University of South Wales, Corresponding \\ Address: Girne Mah. Ciftlikli Sok. 21/5; 34852 Maltepe/Istanbul/Turkey \\ Susanne Durst \\ susanne.durst@his.se | School of Business, University of Skövde, Högskolevägen, 54128 Skövde \\ (Sweden) \& South Ural State University, 76 Lenin str., Chelyabinsk (Russian Federation)
}

\begin{abstract}
This article aims to provide a conceptual framework for small and medium-sized enterprises (SMEs) to evaluate the appropriation of blockchain technology for their business needs and challenges. This conceptual framework aims to respond to the problem of increasing speculations surrounding the blockchain that is considered to be an absolute and innovative solution to many business related problems. However, this argument might not be realistic for SMEs despite this assumption. The main argument of the article is that SMEs should be skeptical while evaluating the appropriation of this technology for their business needs and they should follow a tailored approach whilst adopting it. Otherwise, the likelihood is high that a short-term and unstructured knowledge management process to adopt blockchain will end up with a waste of resources. The present paper conceptualizes an appropriation framework within nine factors namely, reduction of costs, internalization, digital representation of assets, unalterable data recording, network size, transparent and synchronized ledger, scalability, fair trade, and financing. Given the field's infancy state of development, the paper relies on a qualitative document analysis involving SME literature and extant literature and white papers of blockchain applications.
\end{abstract}

Keywords. Business Management, Knowledge Management, Small and Medium-sized Enterprises, New Technology, Information Processing, Business Data Processing.

Cite paper as: Ilbiz, E., Durst, S., (2019). The Appropriation of Blockchain for Small and Medium-sized Enterprises, Journal of Innovation Management, www.open-jim.org, 7(1), 26-45. HANDLE: https://hdl.handle.net/10216/119830; DOI: https://doi.org/10.24840/2183-0606_007.001_0004 


\section{Introduction}

Since its first launch in 2009, world's first cryptocurrency Bitcoin had gained gradual global media attention in line with its increasing price. The interest on Bitcoin peaked in December 2017 when its price hit almost $\$ 20.000$ (Coinmarkecap, 2018). Whilst the increasing price of Bitcoin is criticized by senior financial executives as the biggest bubble in the global economy, its distributed ledger technology (DLT) or in other words blockchain technology that enable peer to peer value transaction has been praised from the same financial circles (Cao, 2018). While Bitcoin price shows a fluctuating trend in recent times, there is an increasing demand for adopting the blockchain in different business sectors (Kshetri, 2018).

Despite growing interest in adopting the blockchain technology, the lack of a clear roadmap in the adaptation of this technology raises significant confusion whether the DLT's are an appropriate technology for businesses that have an intention to use it. Even though this technology is considered applicable to bigger firms, i.e. those having strong knowledge management capabilities and relying on both their financial and human resources; appropriateness of this technology to SMEs that often suffer from resource constraints (Jarillo, 1989) is a significant question that needs to be answered considering their impact on the prosperity of countries (OECD, 2017a). In this respect, this study aims to develop a conceptual roadmap for SMEs whether DLTs are an appropriate technology to respond to their needs.

The use of blockchain in business management is a new field of research. Some studies available focus on presenting broader concepts about DLTs, its challenges and its future implications in business management (Swan, 2015; Mougayar, 2016; Tapscott and Tapscott, 2016; Morabito, 2017; Mendling et al., 2018; Zhao et al., 2016; Mainelli and Smith, 2015). These descriptive studies provide a comprehensive overview to practitioners and academicians how to adopt this new technology either in their businesses or their research areas.

In another strand of literature, blockchains are examined under the theme of Business Process Management (BPM). In these papers, the potential benefits of shared ledgers are demonstrated for business enterprises. According to Hull and others DLTs provide a data-aware process for companies who are seeking innovation for business collaboration (Hull et al., 2016). These ledgers help these companies to track the state of the processes in their business and execute each task using a space-optimized data structure (Lopez-Pintado et al., 2017; García-Bañuelos et al., 2017). They provide transparency for the stakeholders of an organization to understand and monitor their business process (Milani et al, 2016). Due to DLTs having no ownership, they also offer traceability of business data by evaluating blockchain records (Kim and Laskowski, 2016).

The issue of trust in business relationships is one of the major concerns for all parties (Blois, 2002) if they have not been in long-term business interactions. In this respect, the blockchain technology is exemplified as one of the solutions to resolve trust issues between the business partners who have no previous business transaction (Weber et al., 2016). It is also considered a solution to the cost of computation and data storage (Rimba et al., 2017). As a result of all these advantages, blockchain is highly recommended to be taught in business schools (Bheemaiah, 2015).

In all the above-mentioned studies, blockchain technology is presented as a useful tool for bu- 
siness solutions. However, the appropriateness of blockchain for SMEs has not been addressed in the above-mentioned studies. In fact, the authors of this paper have not found any study (nor conceptual or empirical ones) that show the adoption of blockchain technology, which is unsatisfactory considering the relevance of SMEs. Against this background, this article strives to contribute to the emerging field by providing a comprehensive conceptual discussion on blockchain technology in SMEs. It proposes a conceptual framework for SMEs to determine whether DLTs are appropriate solutions to improve their business operation and performance. It incorporates distinct benefits of DLTs under a comprehensive conceptual framework to make it easier for owners or owner-managers of SMEs to evaluate the suitability of DLTs for their present and future business challenges.

The main argument of this article is that DLTs are not always a suitable tool for SMEs to improve their business operations. Before investing in this technology, decision makers in SMEs should critically scrutinize whether the innovative features of blockchain are feasible in their current business processes. A failure to this can be an impair investment and disappointment for the smaller company both by wasting their financial capital and human resources for a futile initiative.

This article conceptualizes the appropriateness of blockchain technology for SMEs within nine factors. These factors reflect the major challenges of SMEs when competing with large companies and which have been stressed in the existing literature. In brief, they are: reduction of costs (Lohrke et al., 2006; Kleindl, 2000; Brouthers and Nakos, 2004), internalization (Lu and Beamish, 2001; Desouza and Awazu, 2006; Liesch and Knight, 1999), digital representation of assets (StPierre and Audet, 2011; Wickramansinghe and Sharma, 2005; Durst, 2008), unalterable data recording (Shiraishi, 2012; Flynn and Davis, 2015), network size (Zain and Ng 2006; Qjala, 2009; Lee et al., 2010), transparent and synchronized ledger (Kasheva et at., 2010), scalability (Sultan, 2011; Marian, 2012), fair trade (Redfern and Snedker, 2002; Davies and Crane, 2010), and financing (Zairani and Zaimah, 2013). For each factor, this paper will provide a brief conceptual framework for decision-makers working in SMEs to determine the applicability of blockchain technology to their business model.

A qualitative document analysis was utilized in this paper to conceptualize the appropriateness framework involving existing literature and white papers on blockchain applications and extant SME literature. Depending on if and when SMEs began to use blockchain technology in their business processes, the factors outlined here will hopefully encourage future research to investigate the efficiency of blockchain in SMEs. These findings may also lead to an alteration of the factors and the addition of new ones. So, this study is likely to be considered as the first attempt and groundwork for conceptualizing the appropriateness of blockchain for SMEs. This situation also means a limitation of the present paper.

The remainder of the article is as follows. Next, a description of blockchain and its types is provided. In this section, derivatives of blockchain such as smart contracts will also be explained. Then the above-mentioned features of blockchain in the context of SMEs will be discussed. In the final section, concluding remarks will be shared to make possible a better adaption of DLTs in SMEs. As the old saying goes, "Necessity is the mother of Invention" and this, indeed, blends the domains of technology expertise and the innovation process. This is, in fact, part of what 
makes innovation happen at the "Front End", also referred to as "Fuzzy Front End" to depict the unstructured nature of the process that actually enacts New Concept Development Process and the final emergence of a New Concept. It is on the multidisciplinary nature of this process and supporting tools and concepts, as well as on why and how it actually happens that this article aims at.

\section{Blockchain in General}

The blockchain is simply a linear data structure containing chained data blocks. These blocks comprise transactions between peers. In order to make a value transaction, peers need a cryptographic key-pair to authorize transactions. One of these keys is called the public key, the other is the private key. The public key acts like a bank account where the value transaction is addressed. The private key is such a password or a signature to authorize the transaction. Combination of both keys creates a secure digital identity (Moser et al., 2013).

When a digital asset is intended to be transacted from $\mathrm{A}$ to $\mathrm{B}$, a new hash value is created using a hash of previous transaction and destination account's public key (B's public key). The new hash value is signed by A's private key (Nakamoto, 2008). These not validated transactions aggregated within a data block by blockchain nodes that perform validating transactions, creating new blocks and maintaining transaction records. The timestamp is another component of the block which is formed with the hash value of the previous block and a nonce which is a random number verifies the hash (Nofer et al., 2017). In order to be added to the blockchain, the block contains valid transactions must be linked with the previous block. To do this, the nodes using their computational power guess the correct nonce (random number) that is combined with the previous block hash and the hash of new block transactions to generate a defined result (proofof-work). The first node that predicts a mathematically challenging process add the new block on the chain and it broadcasts to the other nodes (D'Aliessi, 2016). This process is repeated for each block following and it generates chained secure data blocks called a blockchain.

Once a transaction data is placed in the blockchain, it is not easy to alter it. To make this modification, an attacker must change the transactions not only in the latest block but also in previous blocks those are linked with each other with hash values. This kind of attack needs huge computational power. It is extremely hard to compute all data blocks due to an enormous number of random guesses needed to create new blocks and place them on the blockchain (Bheemaiah, 2015). However, there is one risk called $51 \%$ attack that may endanger the integrity of blockchain. According to this hypothetical risk, if an attacker controls more than $50 \%$ of computational (hashing) power of the blockchain network, it has the chance to solve a block before the remaining of the nodes do it. In the case of this scenario, however, the probability of solving other blocks in a row is reduced for the attacker because other honest nodes continue to mine transactions. It becomes more complicated for an attacker to surpass hashing power of all nodes because the attacker has to cope with not only with the old blocks but also with the new blocks produced by honest nodes (Bheemaiah, 2015; D'Aliessi, 2016). In today's computational standards, execution of such an attack is still less likely to be achieved which makes blockchain highly secure value transaction system. 
The blockchain technology is not only limited to simple value transaction from A to B, but it also provides a platform enabling value transaction on the fulfillment of further arbitrary conditions. This innovation is maintained by adding a new layer of blockchain and it is called smart contracts (Szabo, 1997). The smart contracts enable encoding pre-determined conditions (scripts) for value transaction between two or more parties. The code dictates how the process will take place. Due to code is placed in blockchain; it cannot be altered by anyone. For the autonomous execution of the transaction, all parties must fulfill their pre-determined responsibilities. Otherwise, value transaction never happens. This new version of blockchain eases business process management for companies by removing a trusted third party. Along with that their transaction become faster, cheaper, more efficient and incorruptible (Bheemaiah, 2015).

There is no definitive model of DLT's. Since its first application to Bitcoin, three prominent versions of blockchain came into the forefront. These three versions are categorized as Public Blockchains, Consortium Blockchains and Private Blockchains (Voshmgir and Kalinov, 2017; Mulligan et al., 2018).

Public Blockchains are open to all who would like to join this network. By downloading the digital ledger that keeps a record of all block's transactions, they can see and verify data shared in the DLT. Due to there being no central authority, a copy of the blockchain ledger is stored by every node of the network. The nodes only verify the transaction and compute the data blocks. They cannot manipulate the transactions, because they are not intermediary. Every time a new block is added, the ledger is updated. Records kept by nodes enable replication and synchronization of ledger across the blockchain network. In order to motivate nodes to dedicate their computational power to block producing (mining), consensus algorithms are developed under the name of proof-of-work or proof-of-stake. As mentioned earlier, these algorithms task nodes to solve complex mathematical problems to synchronize the ledger. When they accomplish the task, they are rewarded with incentives such as crypto currencies and these virtual currencies can be exchanged with fiat currencies. Public ledger systems have no infrastructure cost because nodes use their own computational power and their participation in the network is voluntary. However, public blockchains are slow in transaction time and their transaction capacity is limited in comparison to the other ledger types. High energy cost is another weakness of the public ledger system.

Consortium ledgers differentiate from public ledgers by determining who will act as the transaction validator. In public ledgers any one can be a node to validate the transaction, however, in consortium ledgers, developers of consortium either sets a permission mechanism for the nodes to join the network or they can build their own nodes all around the world. In providing publicly available records, transparency mechanism in consortium ledgers works as the same as public ledgers. Consortium ledger technologies also may not build its system to consensus algorithms such as proof of work or proof of stake (Bauerle, 2017b). Due to the absence of the mining process, this type of ledger systems reduces transaction times and computational cost. They are also energy efficient for the sake of preserving natural sources and more scalable in terms of a higher number of transactions (Credits, 2017).

Private blockchains are the strictest version of ledger systems. They neither allow nodes to participate without permission of developer nor the ledger records is visible publicly. It is kind 
of an internal type ledger system for closed community or a network. These blockchains are also criticized for nothing more than any traditional data base (Percic, 2018). If the network does need to share its transaction data or they are very sensitive to data privacy, these ledgers are a more appropriate choice for them. The other benefits of private ledgers are the same as consortium ledgers such as faster transaction times, lower computational costs, lower energy cost and high transaction volume (Voshmgir and Kalinov, 2017).

\section{Blockchain in the Context of SMEs}

Even though there is no globally agreed definition, companies that employ fewer than 250 employees and which has less than 50 million annual turnovers are considered as SMEs (European Commission, 2019). These companies are considered the backbone of most of the economies (Eurostat, 2011) and their survival is vital for a healthy economy. SMEs have to be strengthened to overcome the economic challenges surrounding them (OECD, 2017a).

Globalization is one of the challenges for SMEs that impose new trading conditions to keep up with. In order to compete with their global rivals, SMEs should develop new business strategies based on efficiency, flexibility and their product and process quality must be in higher standards (OECD, 2002). Furthermore, the internationalization of their businesses in foreign markets is considered a critical junction to maximize their business opportunities (Knowles et al., 2006; Shane and Venkataraman, 2000; OECD, 2017a). Nevertheless, growth through internalization, or growth in general, necessitates allocating resources not only financial and physical assets but also investing on intangible assets such as information technology tools for business process management (Alwert et al., 2005). Attaching higher importance to knowledge assets no more considered new for business enterprises (Martín-de-Castro et al., 2006), rather ignoring these resources carry the danger of knowledge attrition (Durst and Wilhelm, 2011).

In order to overcome knowledge attrition and to manage current and future knowledge resources in the best possible manner, SMEs need to rely on efficient Knowledge Management (KM) (Durst and Edvardsson, 2012). Knowledge has increasing importance for firms, regardless of size, in their strategic priority scale (Spender, 1996). If SMEs find ways to adequately manage knowledge, it provides them capabilities to achieve a competitive advantage (Teece, 2001). Knowledge management includes many processes and structures within organizations. The adoption of new innovative technologies is one of the key elements of effective KM (Kluge et al., 2001; Quintas, 2002; O’Dell et al., 2003; Edvardsson, 2009; Jashapara, 2011).

The DLTs or blockchain technology is one of the innovations of recent years that is considered to solve many traditional business-related problems. However, the hype surrounding the blockchain is sometimes misleading the decision makers in companies because of the confusion or the absence of knowledge about this technology. Moreover, a tendency of SMEs to rely on short-term unstructured methods for organizational learning (Beijerse, 2000; Matlay, 2000; McAdam and Reid, 2001; Corso et al., 2003; Bozbura, 2007; Hutchinson and Quintas, 2008) undermines a comprehensive evaluation of appropriateness of blockchain technology for this category of firms. Additionally, the fact that many smaller firms struggle with the adoption of more sophisticated 
ICTs that could help them in benefiting from the opportunities offered by digitalization (OECD, 2017a) should not be overlooked in this context.

In this respect, the innovative features of blockchain should be evaluated together with the major challenges of SMEs. This is done in the following sections.

\subsection{Reduction of Costs}

In comparison to larger firms, SMEs suffer often from resource constraints (Jarillo, 1989; Thong, 2001). This means SMEs have to be more careful using their resources because reversing wastage of resources might not be easier as in larger businesses (Amelingmeyer and Amelingmeyer, 2005). In order to tolerate resource constraints, SMEs have to reduce their operational costs to compete with their bigger rivals.

One of the solutions blockchain provides for SMEs is it removes intermediary for value transaction. For SMEs, this intermediary might be a bank, a broker or a middleman who secures the value transaction between the SMEs and their trading counterpart. Relying on an intermediary inevitably increases transaction costs because of the fees the intermediary takes or the margin they add (Madhok and Tallman, 1998). By using blockchain, the SMEs can reduce their transaction costs and they can compete with bigger firms in the absence of intermediary expenses.

Nevertheless, removing the intermediary every time might not be the ideal solution for SMEs. Under certain circumstances, a trusted party might be needed between two trading partners to regulate their interaction. The intermediary in this respect plays a role to resolve potential conflicts between companies and their absence might be much costly for them. Consequently, in order to decide on the appropriateness of blockchain, decision makers in SMEs should calculate both the cost of an intermediary to the business and the cost of adopting blockchain technology. If the role of the intermediary is expensive than investing in blockchain technology, knowledge transfer and knowledge utilization in blockchain will be much profitable for them. Otherwise, continuing with traditional methods will be a much convenient solution for SME's.

Another important point on removing the intermediary is all parties utilizing blockchain should use this technology in an efficient way. If counterparts of SMEs are not aware of what the blockchain is, then removing an intermediary will make no sense for their business transactions. It will bring other problems between them which will increase their business transaction cost and eliminate the trust among them.

\subsection{Internalization}

Internalization is one of the challenges of SMEs to increase their share in global markets. They need both additional resources (Welch and Luostarinen, 1988) and trusted relationships (Zain and $\mathrm{Ng}, 2006$ ) to successfully implement their internalization strategies. The concern of the loss of resources makes SMEs hesitate to do business with actors who have no available and credible trading record. This hesitation may prevent the execution of a potentially profitable business 
for SMEs and in turn, can mean the loss of this business opportunity to bigger firms who can tolerate this risk easily in comparison to SMEs.

In this respect, smart contracts provide an opportunity for SMEs to do business with untrusted parties. It creates a platform where peers do not need to trust each other. They can make secure value transaction even they have no previous trading record. The SME's using smart contracts can set arbitrary conditions to execute business operation and as long as peers fulfill the predetermined conditions, these contracts autonomously execute value transaction. For instance, whilst company A sends its product to B, the money of B is kept in blockchain escrow and it is released on the condition of safe delivery to company B. When B confirms the safe delivery, the money in escrow can be transferred by company A. In view of this simple transaction, neither A nor B have to know each other. They only have to comply with the conditions they previously agreed. The smart contract will autonomously execute the contract on behalf of trading parties. For the SMEs who are looking for ways to internalization of their business but hesitant to send their products to untrusted customers, smart contracts can be a suitable solution to improve their business opportunities.

However, if the parties in the respective business transaction have no trust issue and they have aligned interests, the adoption of blockchain might not be necessary for SMEs (Mulligan et al., 2018). It would be wise not to spare their limited resources for adoption of the blockchain.

\subsection{Digital Representation of Assets}

The blockchain ledgers are comprised of digital codes. As indicated earlier, by using hash functions, digital assets are represented in blockchain with unique hash codes. This makes it easier for the business counterparts to follow their business process by tracing the codes. The major concern in this regard is these digital codes should not represent the assets that can change form. For instance, if an SME doing apple juice business, blockchain does allow them following up the supply chain from the collection of apples to return into a juice. Due to apples turn into juice, their quantity is transformed from countable apples to liquid. This transformation cannot represent as a digital asset in blockchain because they are no more in the same form. Therefore, the input and output data will be incompatible in blockchain ledger. The reason for any leakage cannot be explained by looking at digital codes whether the reduction is the cause of stolen apples or wastage while apples are squeezed. If an SME aims to trace one certain asset that can be represented digitally, blockchain will satisfy their needs, otherwise, they should search for another option that can respond to their inquiries.

\subsection{Unalterable Data Recording}

If blockchains are used for the purpose of online documentation, they are not flexible systems to tolerate human error. The data recorded in blockchain is unalterable. When a transaction is made between peers and it is validated by nodes there is no way to alter these records in the blockchain. In this respect, peers must be certain about the accuracy of the data when they are confirming the transaction. This issue may not be the ideal solution for SMEs who 
may look for flexible and alterable databases, because SMEs have less formal business processes than bigger enterprises (Singer, 2015). SMEs are more inclined to make mistakes in their data management. Therefore, if SMEs are seeking unalterable data recording system blockchain will be an appropriate solution for their needs, otherwise, they should refrain from investing in the blockchain.

\subsection{Network Size}

The major advantage of blockchain is it eliminates the dependency of peers to a central authority. Its decentralized nature increases the significance of network effect. The potential benefits of blockchain increase as long as the size of the network increases (Carson et al., 2018). Thus, it becomes stronger to the outside attacks as it grows (Bauerle, 2017a).

For SMEs who would like to reap the full benefits of the blockchain, they need to have or be part of a robust and big network that distributed grid of nodes. If a small group of companies aims to use blockchain, they are more vulnerable to the outside attacks due to their computational power can be surpassed by bad outside actors. Therefore, before investing in blockchain, SMEs should consider whether their network capacity will be enough to pervade distributed nodes. If they are sure enough then they should initiate a blockchain network or enter into a blockchain network that is maintained by a big player.

\subsection{Transparent and Synchronized Ledger}

The blockchain can also provide a shared repository which is generated by multiple writers. Shared ledgers have two benefits for business enterprises aiming to use it. Firstly, they provide transparency for untrusted shareholder and none of these parties can corrupt the data. Secondly, a copy of the ledger is kept by each node which is backed up in case of a crash of their data storage tools. The DLTs in that sense support SMEs by providing synchronized data recording systems, if there is a concern of consensus on accurate transaction records. Any conflict in records can be resolved by examining the shared ledger. Therefore, if SMEs needs transparent, synchronized and shared repository blockchain will respond to their needs.

On the other hand, transparent and synchronized ledgers carry the risk of revealing all private transaction information to the blockchain network. All nodes in the blockchain can see who is doing business with whom and what their price margins are. This could be a double-edged sword for SMEs. It can either improve competition between SMEs and companies buying products with higher prices look for other companies offering the products at more reasonable prices. Or, it can endanger the business relationship between the market actors involved due to higher prices may perceive as unfair pricing by the majority of companies and their network can be disrupted. Therefore, before initiating a blockchain project, SMEs should be aware of the transparency issue and its likely consequences. 


\subsection{Scalability}

Scalability is another issue that should be considered to determine the appropriateness of blockchain. The higher transaction speed might be an important expectation for SMEs whilst adopting the blockchain. For instance, a speedy transaction might be important for an SME to make possible a quick payment system.

Most of the well-known public blockchains such as Bitcoin and Ethereum have limitations in scalability. For instance, whilst in Bitcoin blockchain, seven transactions can be made per/second, this rises in Ethereum to 15 per/second (Mendling et al., 2018). In comparison to the Visa which can accomplish 2000 to 50000 transactions per/second, public blockchain technology is quite slow for those SMEs who are seeking scalable value transaction methods. However, consortium and private type blockchains provide solutions to the scalability problem of blockchains. For example, a consortium blockchain called "Red Belly Blockchain" offers 600,000 transactions per/seconds for its customers who use their blockchain platform (Crain et al., 2017). In this respect, SMEs should evaluate their transaction volume how much they needed. If they need higher transaction volumes they should use consortium or private blockchains, if transaction volume is smaller, public blockchains will respond their needs with lower volumes.

Apart from the transaction volume, latency is another issue for the quick value transaction. Due to network congestions, sometimes confirmation of transaction may take longer than centralized value transaction systems. For instance, in Bitcoin blockchain, the average confirmation time is taking 60 minutes, for Ethereum network it takes 3 to 5 minutes. However, in Visa, it is only a second (Mendling et al., 2018). This challenge is now projected to be overcome with private and consortium networks which aim to reduce confirmation time as like centralized systems. In that sense, if SME's looking for quick confirmation in their transaction, they should rely on private or consortium type blockchains. If confirmation is not an urgent matter for them, then public blockchains will be an appropriate solution for their needs.

\subsection{Fair trade}

Global competition may sometimes lead companies to lean on unethical business practices, such as unethical production methods. In order to maximize their profits or competition capabilities, these companies might abuse economic, environmental and social issues associated with their business operations. These issues inevitably necessitate tracing their supply chain practices.

In this respect, blockchain technology can provide a solution for SMEs who would like to demonstrate they are complying with fair trade principles provided by the World Fair Trade Organization (WFTO). The customers who are sensitive to these principles can trace the provenance of the products they purchase through blockchain ledger (Teo, 2018). The transparency provided by blockchain can boost the trust between SMEs and their customers and contribute to a competitive edge. 


\subsection{Financing}

A frequently raised challenge of SMEs to realize their business ambitions is their lack of or access to financial capital (OECD, 2017b). In order to access the necessary financial resources, they can try and get a loan from a bank or get access to alternative financing instruments provided by other financial intermediaries. As for getting a loan, interest rates required by financial institutions might not be attractive to initiate their project, e.g. to grow internationally in view of the higher costs that SMEs may face in comparison with the bigger companies (OECD, 2017b). On the other hand, the audience who could provide financial capital to SMEs might be reluctant due to the increased risks involved in financing or missing profit opportunities. Moreover, SMEs seeking funding may also not want to offer equity for investment (KPMG, 2014). Therefore, SMEs should attract those investors who have a good understanding of SMEs and their way of thinking in order to support their expansion strategies.

In that sense, blockchain technology offers SMEs a fundraising opportunity called Initial Coin Offerings (ICO). In an ICO, the SME who owns a project creates a certain amount of digital token and sells it to the potential investors. These investors buy these tokens in exchange for a service provided by the SME or increasing demand on the token in crypto markets that brings higher profits. This win-win situation enables SMEs to reach the necessary funding they needed, and it provides higher profits to their investors.

The ICO's have both advantages and disadvantages for SMEs. They enable quick and less regulated funding process for SMEs and they do not need to loss of equity. On the other hand, due to ICO's are not regulated in many countries, they might subject to fraud cases if they are complained about by their investors. Therefore, the SMEs should consider both advantages and disadvantages of ICO before they set off this journey.

In line with the above-mentioned discussions the appropriateness of the blockchain framework for SMEs can be summarized as follows:

Table 1. Framework for testing the appropriateness of blockchain technology for SMEs.

\begin{tabular}{lll}
\hline \multicolumn{2}{l}{ Conceptual Framework for Appropriateness of Blockchain for SMEs } \\
\hline Major Challenges & Appropriate & Inappropriate \\
\hline Reduction of Costs & For removing Intermediary & $\begin{array}{l}\text { If intermediary: } \\
\text { Regulates the business } \\
\text { interaction } \\
\text { Resolves the Business } \\
\text { Conflicts }\end{array}$ \\
\cline { 2 - 2 } & & Lacking the ability to use \\
\hline $\begin{array}{l}\text { Internalisation } \\
\begin{array}{l}\text { Digital Representation of } \\
\text { Assets }\end{array}\end{array}$ & Untrusted business interac- \\
tion (Smart Contracts) & Intransmutability & Transmutability \\
\hline
\end{tabular}




\begin{tabular}{|c|c|c|c|}
\hline \multicolumn{4}{|c|}{ Conceptual Framework for Appropriateness of Blockchain for SMEs } \\
\hline Major Challenges & \multicolumn{2}{|l|}{ Appropriate } & Inappropriate \\
\hline $\begin{array}{l}\text { Unalterable Data } \\
\text { Recording }\end{array}$ & \multicolumn{2}{|l|}{ No flexibility } & Flexibility is needed \\
\hline Network Size & \multicolumn{2}{|l|}{ Bigger Network } & Small Network \\
\hline \multirow{2}{*}{$\begin{array}{l}\text { Transparent and } \\
\text { Synchronized Ledger }\end{array}$} & \multicolumn{2}{|c|}{ If incorruptible data is needed } & \multirow{2}{*}{ Confidential transaction } \\
\hline & \multicolumn{2}{|c|}{ Competitive Market } & \\
\hline \multirow[t]{2}{*}{ Scalability } & $\begin{array}{l}\text { Higher Tran- } \\
\text { saction Volume } \\
\text { (Private and } \\
\text { Consortium } \\
\text { DLTs) }\end{array}$ & $\begin{array}{l}\text { Lower } \\
\text { Transaction } \\
\text { Volume (Public } \\
\text { DLT) }\end{array}$ & \\
\hline & $\begin{array}{l}\text { Short Latency } \\
\text { (Private and } \\
\text { Consortium } \\
\text { DLTs) }\end{array}$ & $\begin{array}{l}\text { Long Latency } \\
\text { (Public DLT) }\end{array}$ & \\
\hline Fair Trade & \multicolumn{2}{|c|}{$\begin{array}{l}\text { Sensitive in Tracing Prove- } \\
\text { nance of Products }\end{array}$} & No sensitivity \\
\hline Financing & \multicolumn{2}{|c|}{$\begin{array}{l}\text { Less regulated funding } \\
\text { No loss of equity }\end{array}$} & $\begin{array}{l}\text { Risks of fraud } \\
\text { investigations }\end{array}$ \\
\hline
\end{tabular}

\section{Conclusion}

The enthusiasm over blockchain in recent years draws a promising picture that this technology can be a solution to many problems of SMEs. It may help SMEs in different sectors including agriculture, financial services, healthcare, insurance, property management, technology and utilities (Carson et al., 2018). In theory, these arguments have convincing points to overcome the above-mentioned problems. However, this technology is still in an immature stage and a few years are needed to see feasible applications of blockchain in the SME world.

Even though blockchain has the potential of providing cost efficient and transparent solutions to SMEs, the adoption of this technology might not be necessary to respond to these companies needs in a successful manner. The hype around this technology should not deceive owners and owner-managers that every aspect of blockchain is useful for their companies. It is strongly recommended that smaller companies who are interested in this technology and its application should thoroughly evaluate the pros and cons of this technology skeptically and when they are fully certain, then, they should adopt it. They should also remember that those firms who adopt this technology first will have a leading edge over their rivals. 
The blockchain also provides a different alternative for SMEs to use it in their BPM. In that sense, SMEs should follow a tailored approach to pick the right blockchain application to respond to their needs. Choosing the right blockchain model for SMEs necessitates given higher priority to KM. As with the information and knowledge picked up here and there, blockchain will not bring the desired benefits but mainly disappointments. SMEs that aim to benefit from this technology should follow proper knowledge management process.

Even though a small group of SMEs manages to accomplish adopting blockchain technology to their business model, without robust and bigger network benefits of this technology will be not at the required level for them. Therefore, more SMEs should be part of this network to maximize its advantages. In order to attract more SMEs to use blockchain technology, global and national trade unions or organizations should encourage and guide SMEs on how to use this technology. They should provide them with incentives and knowledge management programmes to adopt this technology in their business routine.

Moreover, due to this technology is very novel, there is huge confusion on global and national policy makers to regulate this technology. The absence of globally agreed regulation inevitably increases confusion and hesitation on the companies to benefit from blockchain technology, because of potential money laundering investigations. In order to remove ambiguity upon the blockchain, a global regulative framework should be submitted as soon as possible by international trade organizations to encourage more companies to use it securely.

As for the final note, this article was the first step to integrate blockchain technology into SME related future projects. Based on the ideas discussed in the paper and the framework proposed, a number of future research avenues can be derived in order to investigate the appropriateness of applying blockchain in SMEs. In a next step, it is suggested to empirically study the nine factors and their suitability in SMEs. Additionally, future research could either investigate all the nine factors individually or in combination to find out whether blockchain can improve business operations in SMEs, and if yes, how. It is also recommended to focus on certain industries, e.g., smaller financial intermediaries and company size, e.g., small companies, to develop an in-depth understanding of blockchain in SMEs.

\section{References}

Alwert, K., Heisig, P., \& Mertins, K. (2005). Wissensbilanzen - intellektuelles kapital erfolgreich nutzen und entwickeln. In K. Mertins, K. Alwert \& P.Heisig (Eds.), Intellektuelles Kapital Erfolgreich Nutzen und Entwickeln, (pp.1-17). Berlin, Heidelberg, New York: Springer.

Amelingmeyer, J., \& Amelingmeyer, G. (2005). Wissensmanagement beim Führungswechsel in KMU. In J.A. Meyer (Ed.) Wissens- und Informationsmanagement in kleinen und mittleren Unternehmen, (pp. 479-488). Lohmar, Cologne: Josef Eul Verlag.

Bauerle, N. (2017a). What are Blockchain's Issues and Limitations? Accessed 15th July 2018. https://www.coindesk.com/information/blockchains-issues-limitations/.

Bauerle, N. (2017b). What is the Difference Between Public and Permissioned Blockchains? Ac- 
cessed 14th July 2018. https://www.coindesk.com/information/what-is-the-difference-betweenopen-and-permissioned-blockchains/.

Beijerse, R.P. (2000). Knowledge management in small and medium-sized companies: knowledge management for entrepreneurs. Journal of Knowledge Management, 4(2), 162-79.

Bheemaiah, K. (2015). Why Business Schools Need to Teach About the Blockchain? Accessed 28th July 2018. SSRN https://ssrn.com/abstract $=2596465$

Blois, K. J. (1999). Trust in Business to Business Relationships: An Evaluation of its Status. Journal of Management Studies, 36, 197-215.

Bozbura, F.T. (2007). Knowledge management practices in Turkish SMEs. Journal of Enterprise Information Management, 20(2), 209-21.

Brouthers, K.D, \& Nakos, G. (2004). SME Entry Mode Choice and Performance: A Trasaction Cost Perspective. Entrepreneurship Theory and Practice, Spring, 229-247.

Cao, S. (2018). JP Morgan CEO Jamie Dimon: Blockchain is Real, Not Interested in Bitcoin. Accessed 14th July 2018. http://observer.com/2018/01/jp-morgan-jamie-dimon-blockchain-realnot-interested-bitcoin/.

Carson, B., Romanelli, G., Walsh, P., \& Zhumaev, A. (2018). Blockchain beyond the hype: What is the strategic business value? Accessed 15th July 2018. https://www.mckinsey.com/businessfunctions/digital-mckinsey/our-insights/blockchain-beyond-the-hype-what-is-the-strategic-businessvalue? cid=other-eml-nsl-mip-mck-oth-1807\&hlkid $=5424 \mathrm{a} 29008 \mathrm{e} 445239371 \mathrm{a} 81 \mathrm{cc} 83 \mathrm{~b} 3 \mathrm{dbb} \&$ hctky $=2254153 \& \mathrm{hd}$ 458b-4b4e-a1ee-ad99e602294e.

Coinmarkecap, (2018). Cryptocurrency Market Capitalizations. Accessed 14th July 2018. https://coinmarketcap.com/.

Corso, M., Martini, A., Paolucci, E., \& Pellegrini, L. (2003). Knowledge management configurations in Italian small-to-medium enterprises. Integrated Manufacturing Systems, 14(1), 46-57.

Crain, T., Gramoli V., Larrea M., \& Raynal M. (2017). Leader/Randomization/Signature-free Byzantine Consensus for Consortium Blockchains. Accessed 15th July 2018.

https://csrg.redbellyblockchain.io/doc/ConsensusRedBellyBlockchain.pdf

Credits, (2017). Is a blockchain without mining possible? Accessed 14th July 2018. https://medium.com/@credi a-blockchain-without-mining-possible-9db40edec8b0.

D'Aliessi, M. (2016). How Does the Blockchain Work? Accessed 14th July 2018. https://medium.com/@michele does-the-blockchain-work-98c8cd01d2ae.

Davies, I.A., \& Crane, A. (2010). Corporate social responsibility in small-and medium-size enterprises: investigating employee engagement in fair trade companies. Business Ethics A European Review, 19(2), 126-139.

Desouza, K.C., \& Awazu, Y. (2006). Knowledge management at SMEs: five peculiarities. Journal of Knowledge Management, 10(1), 32-43. 
Durst, S. (2008). The relevance of intangible assets in German SMEs. Journal of Intellectual Capital, 9(3), 410-432.

Durst, S., \& Edvardsson, I. R. (2012). Knowledge Management in SMEs: A Literature Review. Journal of Knowledge Management, 16(6), 879 - 903.

Durst, S., \& Wilhelm, S. (2011). Knowledge management in practice: insights into a mediumsized enterprise's exposure to knowledge loss. Prometheus, 29(1), 1-16.

Edvardsson, I.R. (2009). Is knowledge management losing ground? Developments among Icelandic SMEs. Knowledge Management Research \& Practice, 7(1), 91-99.

European Commission, (2019). The new SME definition: user guide and model declaration. Accessed 16th May 2019.

http://ec.europa.eu/growth/smes/business-friendly-environment/sme-definition/

Eurostat, (2011). Key Figures on European Business with a Special Feature on SMEs. Accessed 27th July 2018. http://ec.europa.eu/eurostat/documents/3930297/5967534/KS-ET-11-001EN.PDF/81dfdd85-c028-41f9-bbf0-a9d8ef5134c5.

Flynn, A. \& Davis, P. (2015). The policy-practise divide and SME-friendly public procurement. Environment and Planning C: Politics and Space, 34(3), 559-578.

García-Bañuelos, L., Ponomarev, A., Dumas, M., \& Weber, I. (2017). Optimized Execution of Business Processes on Blockchain. In J. Carmona, G. Engels \& A. Kumar (Eds.), Business Process Management, (pp.130-146). Cham: Springer.

Hull, R., Batra, V.S., Chen, YM., Deutsch, A., Heath III, F.F.T., \& Vianu, V. (2016). Towards a Shared Ledger Business Collaboration Language Based on Data-Aware Processes. In: Q. Sheng, E. Stroulia, S. Tata \& S. Bhiri (Eds.), Service-Oriented Computing, (pp.18-36). Cham: Springer.

Hutchinson, V., \& Quintas, P. (2008). Do SMEs do knowledge management? Or simply manage what they know? International Small Business Journal, 26(2),131-154.

Jarillo, J.C. (1989). Entrepreneurship and growth: the strategic use of external resources. Journal of Business Venturing, 4(2),133-147.

Jashapara, A. (2011). Knowledge Management: An Integrated Approach. Harlow: Prentice Hall.

Kasheva, M., Atanasova, T., Kisimov, V., Sulova, S., \& Vasilev, J. (2010). Bulgarian project, A methodology for design and implementation of a distributed business intelligent system for SMEs, The 33rd International Convention MIPRO. 24-28 May 2010. 1-4. Opatija, Crotia.

Kim, H., \& Laskowski, M. (2016). Towards an Ontolgy-Driven Blockchain Design for Supply Chain Provenance. Accessed 28th July 2018. SSRN https://ssrn.com/abstract=2828369.

Kleindl, B. (2000). Competitive Dynamics and New Business Models for SMEs in the Virtual Marketplace. Journal of Developmental Entrepreneurship, 5(1), 73-85.

Kluge, J., Wolfram, S., \& Licht, T. (2001). Knowledge Unplugged: The McKinsey 85 Company Global Survey on Knowledge Management. Houndsmills: Palgrave. 
Knowles, D., Mughan, T., \& Lloyd-Reason, L. (2006). Foreign language use among decisionmakers of successfully internationalised SMEs. Journal of Small Business and Enterprise Development, 13(4), 620-641.

KPMG (2014) Financing Family Business growth through individual investor. Accessed 14th January 2018. https://kpmgfamilybusiness.com.

Kshetri, N. (2018). Blockchain's roles in meeting key supply chain management objectives. International Journal of Information Management, 39, 80-89.

Lee, S., Park, G., Yoon, B., \& Park, J. (2010). Open innovation in SMEs-An intermediated network model. Research Policy, 39(2), 290-300.

Liesch, P.W. \& Knight, G.A. (1999). Information Internalization and Hurdle Rates in Small and Medium Enterprise Internalization. Journal of International Business Studies, 30(2), 383394.

Lohrke, F.T., Franklin G.M.,\& Frownfelter-Lohrke, C. (2006). The Internet as an Information Conduit: A Transaction Cost Analysis Model of US SME Internet Use. International Small Business Journal, 24(2), 159-178.

Lopez-Pintado, O., Garcia-Banuelos, L., Dumas, M., \& Weber, I. (2017). Caterpillar: A Blockchain-Based Business Process Management System. Accessed 28th July 2018.

https://pdfs.semanticscholar.org/11ae/5b0bb3795a1502f17689ddbd92ffaeead665.pdf?_ga=2.229071900.107842 39183498.1531562464.

Lu. J.W, \& Beamish. P.W. (2001) The Internalization and performance of SMEs. Strategic Management Journal, 22(6-7), 565-586.

Madhok, A., \& Tallman, S. (1998). Resources, Transactions and Rents: Managing Value Through Interfirm Collaborative Relationships. Organization Science, 9(3), 326-339.

Mainelli, M., \& Smith, M. (2015). Sharing Ledgeers for Sharing Economies: An Exploration of Mutual Distributed Ledgers. Journal of Financial Perspectives, 3(3), 1-47.

Marian, M. (2012). Guidelines for Increasing the Adoption of Cloud Computing within SMEs, The Third International Conference on Cloud Computing, GRIDS and Virtualization, 22-27 July 2012. 7-10. Nice, France.

Martín de Castro, G., Navas-López, J., López Sáez, P., \& Alama-Salazar, E. (2006). Organisational capital as competitive advantage of the firm. Journal of Intellectual Capital, 7(1), $324-337$.

Matlay, H. (2000). Organisational learning in small learning organisations: an empirical overview. Education + Training, 42(4/5), 202-211.

McAdam, R., \& Reid, R. (2001). SME and large organisation perceptions of knowledge management: comparisons and contrasts. Journal of Knowledge Management, 5(3), 231-241.

Mendling, J., Weber, I., Van Der Aalst, W., Brocke, J. V., Cabanillas, C., Daniel, F., Debois, S., Di Ciccio, C., Dumas, M., Dustdar, S., Gal, A., Garcia-Banuelos, L., Governatori, G., Hull, R., La Rosa, M., Leopold, H., Leymann, F., Recker, J., Reichert, M., Reijers, H.A., Rinderle-Ma, S., 
Solti, A., Rosemann, M., Schulte, S., Singh, M.P., Slaats,T., Staples, M., Weber, B., Weidlich, M., Weske, M., Xu, X., \& Zhu, L. (2018). Blockchains for Business Process Management Challenges and Opportunities. ACM Transactions on Management Information Systems, 9(1), $1-16$.

Milani, F. P., Garcia-Banuelos, L., \& Dumas, M. (2016). Blockchain and Business Process Improvement. Accessed 14th July 2018. https://www.bptrends.com/blockchain-and-businessprocess-improvement/.

Morabito, V. (2017). Business Innovation Through Blockchain The B3 Perspective. Cham: Springer.

Moser, M, Bohme, R., \& Breuker, D. (2013). An inquiry into money laundering tools in the Bitcoin ecosystem, 2013 APWG eCrime Researchers Summit, 17-18 September 2013. 1-14. San Francisco, CA, USA.

Mougayar, W. (2016). The business blockchain: promise, practice, and application of the next Internet technology. Hoboken, New Jersey: John Wiley \& Sons.

Mulligan, C., Scott, J. Z., Warren, S., \& Rangaswami, J.P. (2018). Blockchain Beyond the Hype: A Practical Framework for Business Leaders. Accessed 14th July 2018. World Economic Forum http://www3.weforum.org/docs/48423_Whether_Blockchain_WP.pdf.

Nakamoto, S. (2008). Bitcoin: A Peer-to-Peer Electronic Cash System. Accessed 28th July 2018. https://bitcoin.org/bitcoin.pdf

Nofer, M., Gomber, P., Hinz, O., \& Schiereck, D. (2017). Blockchain. Business $\&$ Information Systems Engineering, 59(3), 183-187.

O'Dell, C., Hubert, C., Lopez, K., Odem, P. \& Raybourn, C. (2003). Successful KM implementations: a study of best-practice organizations. In C.W. Holsapple (Ed.), Handbook on Knowledge Management, (pp. 411-441). Berlin: Springer.

OECD, (2002). Small and Medium Enterprise Outlook. Accessed 28th July 2018.

http://www.insme.org/files/126

OECD (2017a) Enhancing the Contributions of SMEs in a Global and Digitalised Economy. Accessed on 20th July 2018. https://www.oecd.org/mcm/documents/C-MIN-2017-8-EN.pdf

OECD (2017b) Financing SMEs and Entrepreneurs 2017. AN OECD SCOREBOARD. Accessed 20th July 2018. https://www.oecd.org/employment/financing-smes-and-entrepreneurs$23065265 . h t m$

Percic, L. (2018). Public vs. Permissioned (Private) Blockchains. Accessed 14th July 2018. https://medium.com/iryo-network/public-vs-permissioned-private-blockchains-99c04eb722e5.

Qjala, A. (2009). Internalization of knowledge-intensive SMEs: the role of network relationships in the entry to a psychically distant market. International Business Review, 18(1), 50-59.

Quintas, P. (2002). Managing knowledge in a new century. In S. Little, P. Quintas \& T.S. Ray (Eds.), Managing Knowledge: An Essential Reader, (pp. 1-14). London: The Open University of Sage Publications. 
Redfern, A. \& Snedker, P. (2002). Creating Market Opportunities for Small Enterprises: Experiences of the Fair-Trade Movement. Geneva: International Labour Office.

Rimba, P., Tran, A.B., Weber, I., Staples, M., Ponomarev, A., \& Xu, X. (2017). Comparing Blockchain and Cloud Services for Business Process Execution, 2017 IEEE International Conference on Software Architecture (ICSA), 3-7 April 2017. 1-4. Gothenburg, Sweden.

Shane, S. \& Venkataraman, S. (2000). The promise of entrepreneurship as a field of research. Academy of Management Review, 25(1), 217-226.

Shiraishi, Y. (2012). Eco-design promotion in SMEs by material flow analysis of supply chain: case studies and modeling. In M. Matsumoto, Y. Umeda, K. Masui \& S. Fukushige (Eds.), Design for Innovative Value Towards a Sustainable Society, (pp. 946-651). Dordrecht: Springer.

Singer, R. (2015, April). Business process management in small-and medium-sized enterprises: an empirical study. In Proceedings of the 7 th International Conference on Subject-Oriented Business Process Management (p. 9). ACM.

Spender, J.C. (1996). Making knowledge the basis of a dynamic theory of the firm. Strategic Management Journal, 17(S2), 45-62.

St-Pierre, J. \& Audet, J. (2011). Intangible assets and performance: Analysis of manufacturing SMEs. Journal of Intellectual Capital, 12(2), 202-223.

Sultan, N. A. (2011). Reaching for the "cloud": How SMEs can manage. International Journal of Information Management, 31(3), 272-278.

Swan, M. (2015). Blockchain: blueprint for a new economy. California: O'Reilly.

Szabo, N. (1997). Formalizing and Securing Relationships on Public Networks. Accessed 28th July 2018. http://ojphi.org/ojs/index.php/fm/article/view/548/469.

Tapscott, D., \& Tapscott, A. (2016). Blockchain revolution: how the technology behind bitcoin is changing money, business, and the world. New York: Portfolio/Penguin.

Teece, D.J. (2001). Strategies for managing knowledge assets: the role of firm structure and industrial context. In I. Nonaka \& D.J. Teece. (Eds.), Managing Industrial Knowledge, Creation, Transfer and Utilization, (pp. 125-144). London: Sage.

Teo, C. (2018). From diamonds to recycling: how blockchain can drive responsible and ethical businesses. Accessed 15th July 2018. World Economic Forum https://www.weforum.org/agenda/2018/06/diamon recycling-blockchain-technology-responsible-ethical-businesses/.

Thong, J.Y.L. (2001). Resource constraints and information systems implementation in Singaporean small businesses. Omega, 29(2), 143-156.

Voshmgir, S. \& Kalinov, V. (2017). Blockchain Handbook: A Beginners Guide. Accessed 14th July 2018. https://blockchainhub.net/blockchain-technology/.

Weber, I., Xu, X., Riveret, R., Governatori, G., Ponomarev, A., \& Mendling, J. (2016). Untrusted Business Process Monitoring and Execution Using Blockchain. In M. La Rosa, P. Loos, O, Pastor. (Eds.) Business Process Management, (pp. 329-347). Cham: Springer. 
Welch, L.S., \& Luostarinen, R. (1988). Internationalization: evolution of a concept. Journal of General Management, 14, 34-55.

Wickramansinghe, N. \& Sharma, S. K. (2005). Key factors that hinder SMEs in succeeding in today's knowledge-based economy. International Journal of Management and Enterprise Development, 2(2), 141-158.

Zain, M. \& Ng, S. I. (2006). The impacts of network relationships on SMEs' internationalization process. Thunderbird Int'l Bus Rev, 48, 183-205.

Zairani, Z. \& Zaimah, Z.A. (2013). Difficulties in Securing Funding from Banks: Success Factors for Small and Medium Enterprises (SMEs). Journal of Advanced Management Science, 1(4), 354-357.

Zhao, J. L., Fan. S., \& Yan, J. (2016). Overview of business innovations and research opportunities in blockchain and introduction to the special issue. Financial Innovation 2(1), 1-7. 


\section{Biographies}

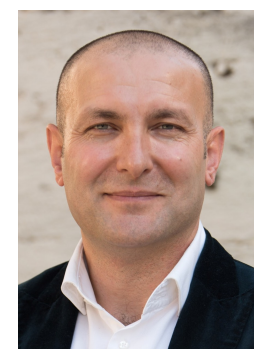

Ethem Ilbiz. Dr Ethem Ilbiz is a visiting research fellow in policing and security at the University of South Wales who has a special research interest about practical demonstrations of issues at the crossroads of disruptive technologies and policy. His recent research projects include knowledge risk management of blockchain technology, obfuscation techniques in virtual currencies and the illicit use of virtual currencies in evading the international regimes for countering the financing of terrorism, antimoney laundering and cybercrime. He also works on a new theoretical governance model called Uberisation that is inspired by Uber which is used as a cooperation model engaging multiple actors under a sharing platform. Apart from his recent research interests, he did his $\mathrm{PhD}$ at the School of Politics and International Relation at the University of Nottingham.

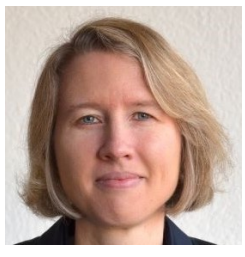

Susanne Durst. Susanne Durst is a Professor of Business Administration at the School of Business at University of Skövde (Sweden), a Visiting Professor of Business Administration at Universidad del Pacífico (Peru), and an Associate Professor at South Ural State University (Russian Federation). She is also the leader of the research group knowledge, innovation and marketing (KIM) at the School of Business at University of Skövde. Her research interests include small business management SME business transfers, strategic knowledge management, knowledge risk management, (open) innovation and corporate governance. She has been conducting several national and international research projects on company succession, corporate governance, and knowledge management in SMEs and public organizations. Her work has been recognized through different awards, including the Transeo Academic Award in 2012 and has been published in international peer-reviewed journals. Before joining academia, she worked in different positions with private enterprises of different industries and size.

\section{ISSN 2183-0606}

http://www.open-jim.org

http://creativecommons.org/licenses/by/3.0 